\title{
Coordenação pedagógica na escola: dilemas de uma identidade profissional oscilante
}

\section{Pedagogical coordination in school: dilemmas of an oscillating professional identity}

Vanja Maria Dominices Coutinho Fernandes ${ }^{1 *}$, Cristiane Dutra Ribeiro Habibe ${ }^{1}$, Leila Fernanda Mendes Everton Rego ${ }^{1}$, Valda Ribeiro da Cruz Silva ${ }^{1}$, Francisca das Chagas dos Passos Silva ${ }^{1}$

\section{RESUMO}

Estudos na área apontam alguns entraves ocorrentes na atuação do coordenador pedagógico para o exercício de suas funções e atribuições de maneira objetiva e significativa. Tal problemática foi alvo de nossas inquietações e nos motivou a fazer este estudo para discutir as principais dificuldades enfrentadas pela coordenação pedagógica que resultam em uma identidade profissional não consolidada, gerando incertezas e práticas pedagógicas desvinculadas de suas verdadeiras atribuições. Assim, além de considerarmos o olhar de nossas experiências enquanto atuantes na área, fundamentamos este estudo em teóricos como: TARDIF (2014), ALMEIDA E PLACCO (2012), IMBERNÓN (2011), LIBÂNEO (2004), entre outros. Os resultados da pesquisa mostraram instabilidade entre saber o que precisa ser feito e realmente fazê-lo. Isto é, dilemas quanto ao ser coordenador em sua função precípua (formador de formadores) os quais são reais e difíceis de serem gerenciados enquanto esse profissional não compreender e se mobilizar para o exercício das suas reais atribuições. Isso requer organização, conhecimento autonomia e autoformação.

Palavras-chave: Coordenação Pedagógica; Identidade Profissional; Dilemas;

\section{ABSTRACT}

Studies in the area point to some obstacles that occur in the role of the pedagogical coordinator for the exercise of his functions and attributions in an objective and meaningful way. This issue was the target of our concerns and motivated us to make this study to discuss the main difficulties faced by the pedagogical coordination that result in an unconsolidated professional identity, generating uncertainties and pedagogical practices detached from their true attributions. Thus, besides considering the look of our experiences while working in the area, we base this study on theorists such as: TARDIF (2014), ALMEIDA AND PLACCO (2012), IMBERNÓN (2011), LIBÂNEO (2004), among others. The survey results showed the instability between knowing what needs to be done and actually doing it. That is, dilemmas about being a coordinator in his primary role (trainer of trainers) are real and difficult to manage until this professional understands and mobilizes himself to perform his real duties. This requires organization, knowledge, autonomy and self-training.

Keywords: Pedagogical Coordination; Professional Identity; Dilemmas;

${ }^{1}$ Universidade Federal do Maranhão/UFMA; *E-mail: vanja.dominices@ufma.br; Mestre e Doutora em Educação; http://orcid.org/0000-0002-2756-1938; Coordenadora e Professora Permanente do Programa de Pós Graduação Gestão de Ensino da Educaçao Básica/PPGEEB/UFMA 


\section{INTRODUÇÃO}

No universo escolar a coordenação pedagógica assume a árdua, necessária e importante função de gerenciar os aspectos pedagógicos norteadores e presentes no cotidiano escolar. Assim, indiscutivelmente o coordenador pedagógico precisa ser o articulador/mobilizador das ações educativas que ocorrem dentro e fora da sala de aula, bem como ter a responsabilidade em orientar e acompanhar todos os envolvidos no processo de ensino e aprendizagem dos alunos, fornecendo os encaminhamentos essenciais para o bom andamento das atividades escolares.

Historicamente, estudos na área apontam alguns entraves ocorrentes na atuação do coordenador pedagógico para o exercício de suas funções e atribuições de maneira objetiva e significativa. Tal problemática foi alvo de nossas inquietações e nos motivou a fazer esse estudo para discutir sobre os possíveis dilemas que circundam a atuação da coordenação pedagógica. É importante ressaltar que, a figura do coordenador pedagógico aqui discutida tem sentido estrito como pedagogos-especialistas, conforme preconizado na Lei de Diretrizes e Bases da Educação Nacional-LDB n.9394/96, que hoje compreende aquele profissional que atua como coordenadores, supervisores e orientadores educacionais, ou seja, tem uma atuação muito mais ampla que antes, quando do advento da citada legislação.

Nessa condição, esse pedagogo, o coordenador, é aquele que assume a organização e orientação de todo o trabalho pedagógico na escola, que vai desde o acompanhamento do professor e rendimento dos alunos até as questões macro, como o projeto político pedagógico da escola. "Em outras palavras, pedagogo é um profissional que lida com fatos, estruturas, contextos, situações referentes à prática educativa em suas várias modalidades e manifestações." (LIBÂNEO, 2010, p.52).

Logo, ao nos referirmos ao coordenador pedagógico, em verdade estamos nos reportando à função exercida por esse pedagogo nas escolas da rede pública de ensino, nos âmbitos estadual e municipal, considerando o olhar de nossas experiências enquanto atuantes na área e fundamentando-nos em contribuições de teóricos como: TARDIF (2014), ALMEIDA E PLACCO (2012), IMBERNÓN (2011), LIBÂNEO (2004), dentre outros.

Portanto, apresentamos um estudo teórico que se configura como uma pesquisa bibliográfica, na qual respondemos à seguinte problemática: quais os dilemas enfrentados 
pelo coordenador pedagógico na escola que contribuem para a instabilidade na construção da sua identidade profissional? Dessa maneira, o objetivo foi discutir as principais dificuldades enfrentadas pela coordenação pedagógica, que resultam em uma identidade profissional não consolidada, gerando incertezas e práticas pedagógicas desvinculadas de suas verdadeiras atribuições.

Para tanto, fez-se necessário pontuarmos quais as funções/atribuições que devem ser exercidas pelo coordenador pedagógico, relacionando-as com as ações efetivas no espaço escolar, identificando e discutindo situações que se configuram em dilemas que interferem na construção da identidade profissional do coordenador pedagógico. Assim, este estudo se justifica como um suporte aos profissionais coordenadores pedagógicos no que tange à reflexão e mobilização de ações que contribuam para a construção de uma identidade profissional mais segura e coerente.

Compreendemos que identidade profissional, conforme assinala Veiga (2012, p. 17) refere-se "ao ser e estar na profissão". Nesse sentido, Nóvoa (1991, p. 34) esclarece que “(...) a identidade não é um dado adquirido, não é uma propriedade, não é um produto. A identidade é um lugar de lutas e conflitos, é um espaço de construção de maneiras de ser e estar na profissão". Isto é, pressupõe ter ciência do que se é, do como fazer e para onde se quer caminhar.

Entendemos como identidade profissional "oscilante" aquela que se apresenta enquanto instável em sua natureza e no decorrer do processo pedagógico. Reflete-se na insegurança e incerteza das atividades que devem ser exercidas pelo coordenador e que causam muitos prejuízos para a qualidade e eficiência de seu trabalho, além de fragilizar a sua natureza profissional.

Para a discussão dessas questões, estruturamos o presente artigo da seguinte forma: na primeira parte tratamos das funções/atribuições do coordenador pedagógico; a segunda, descrevemos os dilemas, desafios e perspectivas da coordenação pedagógica e por fim, elencamos algumas considerações finais sobre a problemática apresentada, deixando margem a outras indagações, visto que não pretendemos esgotar esse estudo.

Assim, percebemos a natureza relevante desta pesquisa, pois visa causar algumas reflexões e mobilizações na atuação da coordenação pedagógica que favoreçam a estabilidade em sua identidade profissional enquanto formador/a. NA ESCOLA?: questões de identidade profissional 
O coordenador pedagógico, como parte do grupo gestor da instituição escolar, é figura essencial para atuar na articulação e contribuição de práticas pedagógicas significativas. No que tange às suas funções, a interação com os docentes é essencial para o desenvolvimento das suas ações, pois, a partir daí, fica mais fácil sugerir caminhos e propor reflexões.

[...] O coordenador pedagógico é um profissional imprescindível para assegurar nas escolas a integração e articulação do trabalho pedagógicodidático: a formulação e acompanhamento da execução do projeto pedagógico-curricular, a organização curricular, a orientação metodológica, a assistência pedagógico-didática aos professores na sala de aula numa relação interativa e compartilhada com o professor e os alunos, colaboração nas práticas de reflexão e investigação, diagnóstico e atendimento de necessidades ligadas ao ensino e aprendizagem dos alunos em conjunto com o professor, atividades de formação continuada, práticas de avaliação da aprendizagem.[...] (LIBÂNEO 2002, p. 74)

Percebemos que o coordenador pedagógico, em decorrência da função que exerce na escola, possui inúmeras tarefas e, por consequência, deve, dentre outras características, ser um líder e, como tal, precisa conquistar a sua equipe. Para tanto, faz-se necessário a constante busca de informação, de estudos e novos conhecimentos, pois a função de coordenação pressupõe uma liderança no trato das questões pedagógicas pois, segundo Libâneo (2004, p. 178) "[...] depende de alguns fatores, tais como: autoridade, responsabilidade, decisão, disciplina e iniciativa."

Nesse contexto, o coordenador é o articulador das ações pedagógicas na escola e por esta razão, há intrínsecos saberes necessários e essenciais para o seu fazer pedagógico.

Reportando-nos ao que aponta Tardif (2014) sobre saberes docentes (disciplinares, curriculares e experienciais) e sua relação com a coordenação pedagógica, podemos concluir que tais saberes não são reduzidos à mera transmissão de conhecimentos originários da sua formação inicial, mas construídos ao longo de sua prática social, na vivência cotidiana na escola, nas interações com os seus pares, bem como, nos momentos formativos internos e externos ao espaço escolar.

Contudo, para o desenvolvimento das funções de coordenação pedagógica e a possibilidade de participação e envolvimento de todos, também se faz relevante a organização de um ambiente democrático que, em quaisquer espaços, não é tarefa fácil, tendo em vista a necessidade de ações coletivas e colaborativas. 
Libâneo (2004, p. 200) revela que "Uma gestão participativa também é a gestão da participação". Isto é, na educação quem ocupa cargos de liderança - como diretor ou coordenador pedagógico - precisam despir-se do posicionamento predominantemente autocrático para possibilitar o desenvolvimento de um clima em que todos contribuam com ideias, críticas e encaminhamentos, pois a gestão e participação pedagógica pressupõem uma educação democrática, assentada nas dimensões do ouvir, sugestionar em benefício do coletivo, revisitar posicionamentos (quando necessário) e primar pela análise e desdobramento do que é imprescindível para o processo de ensino e aprendizagem, da formação do professor e das metas que a escola se propõe em determinada situação ou realidade escolar.

$\mathrm{Na}$ gestão democrática, cabe ao coordenador pedagógico junto com todos os outros membros escolares, possibilitar trocas de saberes e experiências, respeitando individualidades, sem perder de vista a sua atribuição maior na convergência da formação de si e do outro. Para tanto, é necessário, também, que se estabeleça um bom relacionamento entre a equipe docente para a viabilização do trabalho pedagógico. Isto é,

(...) reconhecer que sua ocupação tem uma característica genuinamente interativa, ou seja, está a serviço das pessoas e da organização, delas requerendo uma formação específica a fim de buscar soluções para os problemas, saber coordenar o trabalho conjunto, discutir e avaliar a prática, assessorar os professores e prestar-lhes apoio logístico na sala de aula. (LIBÂNEO, 2004, p.350)

É nesse aspecto interventivo e transformador que se destacam as funções da coordenação pedagógica e o seu papel torna-se relevante no contexto escolar. A ciência e o reconhecimento dessas atribuições e responsabilidades por parte do coordenador contribuem para a melhoria da qualidade do trabalho docente e consequentemente para a aprendizagem dos alunos. Há, então, a necessidade de compreender a sua função precípua como assessor de formação permanente.

\subsection{O Coordenador Pedagógico como assessor de formação permanente}

Uma das principais atividades a serem desenvolvidas pelo coordenador pedagógico é a articulação entre a formação do professor e a maneira como as situações de ensino e aprendizagem dos alunos são organizadas na instituição. Dessa forma, tratase de um profissional que dá sustentação ao projeto pedagógico da escola por meio da formação continuada da equipe de professores. 
A formação continuada docente, considerada nesta pesquisa, é a formação construída no cotidiano escolar, nas reuniões realizadas no horário complementar docente, definidas como os tempos que o professor tem disponível para seus estudos e atividades de formação continuada na e fora da escola, com a gestão do coordenador pedagógico. Ao se colocar no papel de formador do corpo docente, o coordenador pedagógico assume a responsabilidade junto aos professores pela qualidade do ensino na escola, desenvolvendo atividades que buscam uma aprendizagem significativa, assegurando um trabalho harmônico e de qualidade entre a coordenação pedagógica e os professores.

Desse modo, nos alinhamos e concordamos com a assertiva de Marques (2000, p.208):

[...] é preciso que a formação continuada aconteça a cada encontro de estudo por meio dos debates e das reflexões, e que nos embates, possa ser rompida a auto confiança da razão e o fácil consenso teórico onde a rotina, que é auto evidente quebre-se; que se multipliquem os riscos do dissenso, que se dissolva a certeza e a familiaridade, sendo pois, neste exercício de atuação coletiva da escola que a teoria deve ser aprofundada, já que é este aprofundamento que irá permitir se repensar a prática e transformar as diretrizes e as condições operacionais do trabalho pedagógico.

Certamente, o diálogo e a troca de ideias e experiências tornam-se muito favoráveis à medida que possibilitam reflexão e mobilização das práticas pedagógicas. Como já afirmava Freire (2005), a formação, baseada numa perspectiva dialógica, favorece o questionamento do "ser" e do "fazer" docente, pois implica em construção contínua e permanente da identidade profissional do professor.

Assim, um coordenador pedagógico atuante precisa ir além do conhecimento teórico, pois para acompanhar o trabalho pedagógico e estimular os professores, faz-se necessário percepção e sensibilidade para identificar as necessidades tanto dos alunos quanto dos professores, mantendo-se sempre atualizado, buscando fontes de informação e refletindo sobre sua prática em vista a novos encaminhamentos.

Nessas perspectivas, determinando o papel do coordenador pedagógico como uma ação de assessoramento, Imbernón (2011, p.98) aponta que "O assessor deve ajudar a diagnosticar obstáculos que esses professores encontram para chegar a sua própria solução contextualizada". Ou seja, a qualidade de assessor é determinada justamente por essas funções: a de estar à disposição para ajudar e a de ser o diagnosticador de obstáculos no qual ele assume aspectos diferenciadores em sua formação, além de experimentar e 
aprender com os demais. Nesse contexto, assessorar não é apresentar soluções, mas conduzir à reflexão e, por consequência, à tomada de decisões.

Portanto, no contexto de uma assessoria de formação, o coordenador pedagógico assume a posição de "amigo crítico", segundo Imbernón (2011), ou seja, observa, faz análise, detecta as necessidades do professor, para então, poder fazer uma intervenção crítica.

Dessa forma, a ação da coordenação pedagógica no processo de formação continuada docente na escola necessita de diferentes estratégias de trabalho com o objetivo de despertar nos professores o interesse por sua formação. O papel de gestor da formação docente exercido pelo coordenador pedagógico, assim como sua convivência diária com o grupo de professores que trabalham na escola permite a esse profissional conhecer bem seus pares observando seus comportamentos e identificando suas necessidades e limitações.

Para Libâneo (2004, p.179):

Coordenação é um aspecto da direção, significa a articulação e a convergência do esforço de cada integrante de um grupo visando a atingir os objetivos. Quem coordena tem a responsabilidade de integrar, reunir esforços, liderar, concatenar o trabalho de diversas pessoas.

O coordenador, então, sendo o gestor pedagógico da escola, deve estimular a participação dos professores não apenas para frequentarem as reuniões pedagógicas, mas a participarem ativamente das atividades de formação continuada, seja na escola como em qualquer outro ambiente e/ou oportunidade.

Sobre esse aspecto, Libâneo (2004) ressalta algumas tarefas que o coordenador deve desenvolver para a efetivação da formação docente em serviço, tais como: prestar assistência pedagógico-didática aos professores, coordenar grupos de estudo, utilizar, supervisionar e dinamizar o projeto pedagógico como referência de formação continuada, trazer propostas inovadoras para utilização de novos recursos tecnológicos e midiáticos. Ou seja, o coordenador cumpre a função de gestor da aprendizagem docente, sendo o promotor da formação continuada, garantindo que os docentes tenham um espaço de trocas de informações e experiências, de interações que se constituem no fortalecimento de seus saberes construídos no ambiente escolar.

No que tange às relações entre professores para o sucesso do trabalho pedagógico na escola, faz-se necessário a recusa do individualismo e a busca de novas práticas de ensino. As identidades isoladas, construídas historicamente pelos docentes, precisam ser 
superadas e o coletivo profissional necessita ser afirmado. Para tanto, o professor deve se preocupar em participar dos planos de regulação do trabalho escolar, das ações de formação e autoformação continuada e permitir a partilha de tarefas e responsabilidades na rotina educacional.

No entanto, Freire (1998, p.92) alerta que:

O professor que não leva à sério sua formação, que não estuda, que não se esforça para estar à altura de sua tarefa não tem força moral para coordenar as atividades de sua classe. Há professores e professoras cientificamente preparados, mas autoritários a toda prova. O que quero dizer é que a incompetência profissional desqualifica a autoridade do professor.

Neste sentido, há um caminho contínuo e também autônomo em busca de conhecimentos para construir e ressignificar sua prática docente, uma vez que os professores devem se sentir protagonistas do seu processo de formação continuada sob a liderança do coordenador, que, ao assumir uma posição de igualdade e colaboração diagnostica obstáculos, fornece apoio e reflete sobre a sua prática para gerar uma ação transformadora. É o juntar esforços para o enfrentamento dos problemas e a procura de suas soluções.

No entanto, nas interfaces da escola, são observadas inúmeras circunstâncias que, na maioria das vezes, geram dilemas, desafios e exigências ao coordenador pedagógico que os coloca diante de conflitos em relação à sua própria identidade profissional.

\section{A ATUAÇÃo dA COORDENAÇÃo PEDAGógICA NA ESCOLA: dilemas e perspectivas para a construção da identidade profissional}

A escola vem investindo em um trabalho no qual a coordenação pedagógica está voltada para a prática de formação continuada dos professores, pois se entende que é por meio do coordenador pedagógico que é possível realizar junto ao corpo docente um trabalho de excelência para o processo de ensino e aprendizagem.

Tomando por base as nossas vivências enquanto coordenadoras pedagógicas da rede pública municipal e estadual de ensino, percebemos que entre as principais dificuldades da coordenação pedagógica, se destaca a necessidade em garantir, com frequência, momentos de planejamento e reflexão de qualidade junto aos professores, não por falta de competência, mas pela organização da sua rotina de trabalho. Entretanto, o problema pode não ser apenas só o tempo disponível para realizar estudos com a equipe de professores, mas a qualidade e o preparo do coordenador pedagógico na gestão de seu 
trabalho. O coordenador pedagógico deve ter consciência de sua função e saber gerir sua rotina com determinação e dinamismo para que todos os objetivos sejam realmente alcançados.

No ambiente escolar, é comum observar o coordenador pedagógico sendo engolido pelo cotidiano, ocupando a sua rotina com atividades que necessariamente fogem das suas responsabilidades, mas, por motivos diversos e/ou até incerteza quanto às suas atribuições, acaba desviando de suas funções. No entanto, como o seu papel principal é ajudar na formação dos professores e na gestão pedagógica da escola, a proposta é que, aos poucos, ele possa redesenhar as suas funções, legitimando-se como formador e parceiro dos professores. Sobre essa situação Almeida e Placco (2012, p.47) destacam:

O cotidiano do/a coordenador/a pedagógico/a ou pedagógico educacional é marcado por experiências e eventos que o levam, com frequência, a uma atuação desordenada, ansiosa, imediatista e reacional, às vezes frenética [...] Nesse contexto, suas intencionalidades e propósitos são frustrados e suas circunstâncias o fazem responder à situação do momento, "apagando incêndio", em vez de construir e reconstruir esse cotidiano.

Observarmos então que, pela ausência de delimitação das funções de coordenação, este profissional acaba por desempenhar atividades de natureza meramente administrativas e burocráticas, sendo considerado como aquele que é o auxiliar do diretor/gestor escolar. É um "tapa buraco", conforme assinala criticamente Vasconcellos (2002). Isto decorre, infelizmente, da errônea concepção do que seja um coordenador pedagógico, pois ao contrário, ele possui identidade própria e papéis muito bem definidos na escola.

Diante disso, o coordenador pedagógico passa a ser visto como alguém que tem a incumbência de resolver todos os problemas escolares, desde as situações didáticopedagógicas às burocráticas-administrativas. $\mathrm{O}$ que, na maioria das vezes, decorre em função do desvio das suas tarefas primordiais, inerentes à sua função, dentre elas, a de formador de formadores. Com isso, cria-se um ciclo vicioso em que o coordenador acaba por não orientar o trabalho do professor, e este, tende a ficar à mercê do improviso.

Desta forma, como as práticas do professor e do coordenador pedagógico não são estáticas, mas flexíveis, isto é, intencionalmente adaptáveis, é importante que o coordenador tenha em seu fazer cotidiano não apenas rotinas, mas estratégias para que o seu trabalho possa ser direcionado a um fim (objetivo) pré-estabelecido, pois conforme Sacristán, 1983 apud Papi, 2005, p. 38: “[...] esquema prático é uma rotina; um esquema 
estratégico é um princípio regulador a nível intelectual e prático, isto é, uma ordem consciente na acção".

É o estar consciente de suas atribuições, seus papéis, suas funções, com base nos pressupostos teóricos e documentais que regem a sua função na escola. Portanto, um dilema a ser superado por muitos coordenadores pedagógicos, que se encontram em uma constante "corda bamba" em seu fazer profissional.

Até aqui vimos que o importante e inerente papel que o coordenador pedagógico tem é o de ser formador, ou melhor, transformar a escola em um espaço de formação permanente, pois são esses encontros formativos que possibilitam uma reflexão na/sobre a prática docente visando uma postura de mudança.

Sendo assim, constatamos em nossas pesquisas, e até mesmo em nossas experiências que um dos grandes dilemas da coordenação pedagógica é o de construir essa "cultura de formação"; isto é, uma situação que envolve desde a dificuldade do coordenador em identificar as necessidades docentes e gerenciar as formações, quanto do próprio docente em enxergar a sua formação continuada como essencial à sua prática.

Segundo Veiga (2015), a formação está ligada a uma ação inacabada, por isso deve ser permanente, com início e sem fim, vez que estamos em um processo contínuo de formação, de desenvolvimento de nossas práticas. Assim, como já mencionava Freire (1998), aprende quem forma e quem é formador.

É comum vivenciarmos situações nas quais os coordenadores pedagógicos não assumem o seu papel enquanto gestor da formação continuada dos docentes, às vezes, por não possuírem esse pressuposto teórico necessário, ou seja, a capacidade técnica que lhe é exigida para essa atribuição. Consequentemente, esse coordenador pedagógico foge de sua tarefa maior que é a de ser formador, para realizar outras funções, ocupando sua rotina com questões não pedagógicas ou reservando para essas últimas um tempo menor. Portanto, notamos que há inúmeros entraves e desafios de natureza pessoal, cultural e social que o coordenador pedagógico enfrenta em seu cotidiano escolar.

\section{CONSIDERAÇÕES FINAIS}

A ação da coordenação pedagógica na escola é fazer com que a equipe de professores seja colaborativa, os alunos aprendam e as famílias participem do projeto educativo. Ser coordenador pedagógico na contemporaneidade é um desafio, pois não é 
fácil criar situações formativas para os professores (entendendo a formação como um processo contínuo) e materializar o seu plano de formação para atender a equipe escolar. Faz-se necessário clareza de suas atribuições e gerenciamento de uma rotina de trabalho, que garanta o desenvolvimento significativo das suas ações.

As contribuições teóricas apontadas nesta pesquisa nos mostraram que a atuação da coordenação pedagógica na escola deve estar pautada em sua estabilidade profissional, isto é, em saber/exercer o seu verdadeiro papel enquanto formador de formadores. Portanto, diante da sua ação de parceria e assessoramento à equipe docente, é possível intervir e mobilizar o percurso pedagógico junto aos seus pares.

Por meio de algumas pesquisas e das nossas próprias vivências enquanto coordenadoras pedagógicas, observamos a instabilidade entre saber o que precisa ser feito e realmente fazê-lo. Por ser a escola um ambiente dinâmico e, por vezes, imprevisível, o coordenador pedagógico atua em situações recorrentes de natureza não apenas pedagógica, mas administrativa, operacional, entre outras.

Diante do exposto, os resultados da pesquisa nos mostraram que os dilemas quanto ao ser coordenador em sua função precípua (formador de formadores) são reais e difíceis de serem gerenciados enquanto esse profissional não compreender e se mobilizar para o exercício das suas reais atribuições. Isso requer organização, conhecimento autonomia e autoformação.

Nessas perspectivas, se faz necessário que o trabalho do coordenador pedagógico seja pautado em constante parceria com a sua equipe docente em prol da qualidade do ensino e da aprendizagem. Para isso, é importante diagnosticar dificuldades e agir sobre elas. Assim, pelo não esgotamento das discussões, é nosso interesse continuar este estudo tendo em vista a relevância e amplitude da temática. Além da problemática da pesquisa, outras questões precisam ser levantadas e refletidas, como por exemplo: Quais os saberes essenciais à prática da coordenação pedagógica? Como o/a coordenador/a pedagógico/a pode se constituir em um assessor de formação continuada? Isso, certamente, ajudará a não perder de vista as suas verdadeiras atribuições enquanto assessor de formação permanente e contribuir sobremaneira para a construção de sua identidade profissional.

\section{REFERÊNCIAS}

FREIRE, P. Educação na cidade. 6.ed. São Paulo: Cortez, 2005. 
FREIRE, P. Pedagogia da autonomia: saberes necessários à prática educativa. 7.ed. São Paulo: Paz e Terra, 1998.

IMBERNÓN, F. Formação docente e profissional: formar-se para a mudança e a incerteza. 9.ed. Trad. Silvana Cobucci Leite. São Paulo: Cortez, 2011.

LIBÂNEO, J. C. Organização e gestão da escola: teoria e prática. Goiânia: Alternativa, 2004.

LÍBÂNEO, J. C. Ainda as perguntas: o que é pedagogia, quem é o pedagogo, o que deve ser o curso de Pedagogia. In: PIMENTA, Selma Garrido (Org). Pedagogia e pedagogos: caminhos e perspectivas. São Paulo: Cortez, 2002.

LIBÂNEO, J. C. Pedagogia e pedagogos, para quê? São Paulo: Cortez, 2010.

MARQUES, M. O. A formação do profissional da educação. 3.ed. Ijuí:Unijuí, 2000.

NÓVOA, A. (Org.). Vidas de professores. Porto: Porto, 1991.

PAPI, S. de O. G. Professores: formação e profissionalização. São Paulo: JM, 2005.

PLACCO, V. M. N. de S. O coordenador pedagógico no confronto com o cotidiano da escola. In: PLACCO, Vera Maria Nigro de Souza; ALMEIDA, Laurinda Ramalho.

(Orgs.). O coordenador pedagógico e o cotidiano na escola. 5. ed. São Paulo: Loyola, 2012.

TARDIF, M. Saberes docentes e formação profissional. 16. ed. Petrópolis: Vozes, 2014.

VASCONCELLOS, Celso dos Santos. Coordenação do trabalho pedagógico: do projeto político-pedagógico ao cotidiano da sala de aula. São Paulo: Libertad, 2002.

VEIGA, I. P. de A.; D’ÁVILA, C. (Orgs.). Profissão docente: novos sentidos, novas perspectivas. 2. ed. Campinas: Papirus, 2015. 